\title{
Adobe: an environmentally friendly construction material
}

\author{
R. Illampas, I. Ioannou \& D. C. Charmpis \\ Department of Civil and Environmental Engineering, \\ University of Cyprus, Nicosia, Cyprus
}

\begin{abstract}
Adobe is one of the oldest and most widespread forms of construction. Although technologically simple, this material has the potential to produce durable buildings of considerable architectural sophistication that are appropriate for arid climatic conditions and have a wide range of uses. This is true in both vernacular and 'modern' contexts. Moreover, adobe is an environmentally friendly material that does not require additional energy resources for its production and application, it can be fully recycled and it creates minimal levels of waste when disposed. Since most building techniques related to earth-based materials have been systematically neglected during recent decades, there is an imminent need to "rediscover" adobe through academic research. This paper reports the first findings of a research program aiming to examine adobe structures in Cyprus. We present a review of the use of adobe on the island and the main causes of deterioration of adobe structures. We also mention techniques currently used for the restoration of traditional adobe buildings and we report some preliminary laboratory results of tests carried out on local adobes.
\end{abstract}

Keywords: adobe, deterioration, compressive strength, earthen materials.

\section{Introduction}

The construction and servicing of buildings has a big impact on the global environment. In the UK it has been estimated that about $30 \%$ of the country's total energy consumption goes into the servicing of domestic buildings, while a further $8 \%$ goes into the construction of new buildings [1]. In countries with a lesser stock of existing buildings, such as Cyprus, the amount of energy consumed in the construction of new buildings is much greater. 
At the same time, the globalization of the building industry has caused the extensive application of modern construction techniques and materials to both new and historic buildings. These materials rely heavily on energy-intensive manufacturing procedures and application techniques. They are also responsible, to a great extent, for the depletion of the earth's natural resources. With public opinion finally endorsing the need for sustainable development, academic research towards alternative building techniques and materials that have minimal impact on the environment has become eminent. Research related to earth-based construction materials represents part of the fight-back towards a more responsive, environmentally benign approach that preserves and enhances cultural continuity and tradition. Earth-based construction materials, in contrast to most modern inorganic materials, have excellent sustainability characteristics. These include low carbon dioxide emissions $\left(\mathrm{CO}_{2}\right)$, local sourcing and biodegradability. It is worth mentioning that recent studies indicate that the embodied $\mathrm{CO}_{2}$ emissions of earth brick masonry are approximately $22 \mathrm{~kg} /$ tonne whereas concrete block masonry has embodied $\mathrm{CO}_{2}$ emissions equivalent to 143 $\mathrm{kg} /$ tonne [2]. Apart from the minimal environmental footprint that earth-based construction materials have, their application enhances cultural continuity and can help to preserve significant traditional skills and techniques.

\section{Adobe}

Adobe is the best known and one of the most versatile ways of using earth for construction. Adobe bricks have been used for thousands of years and are probably one of the first man-made materials. According to archaeological evidence, the mud brick was invented between 12,000 and 10,000 years ago, while the moulded production of adobe developed in Mesopotamia 7,000 years ago [2]. Adobe structures worldwide range from rather simple low-rise dwelling units to larger ones, such as fortresses, palaces, tombs and temples, some of which have significant aesthetic appeal and historic value. Even today $30 \%$ of the earth's population is housed in earthen structures and these are most commonly built of adobe [3]. Approximately 50\% of the population in developing countries, including the majority of the rural population and at least $20 \%$ of the urban and suburban population, live in earthen dwellings [3]. In addition, several historic monuments of outstanding universal value are constructed of adobe.

The term "adobe" is of Spanish/Arabic origin and is used to describe construction materials, usually mud bricks, which were fabricated from moistened earth and were sun dried [4]. In many places the term is used to describe the material in the fresh state, the dried masonry block and the entire building. Adobe construction materials used in historic structures include sundried brick or block, adobe mortar, cast adobe and rammed earth. Adobe is a mixture of sand, silt and clay, which, when mixed with water to a plastic consistency, can be cast into the desired form, used as mortar between adobe brick or used as plaster. In many instances, straw was added to adobe to increase 
its resistance to cracking, while residual grass and twigs were often present. Adobe also tends to contain varying amounts of small stones or gravel.

Although technologically simple, adobe has the potential to produce durable buildings of considerable architectural sophistication that are appropriate to arid climatic conditions and have a wide range of uses. This is true in both vernacular and 'modern' contexts. It is an environmentally friendly material that does not require additional energy resources for its production and application, it can be fully recycled and it creates minimal levels of waste when disposed. Moreover, it can be applied to the conservation and restoration of existing structures, thus enhancing sustainable development. Despite the fact that the construction of adobe buildings has seized in most countries of the western world, the material is still used in many developing countries of the world. In some developed countries, such as the United States, the United Kingdom, Germany and New Zealand, adobe is currently being used as an alternative, low cost construction material that has minimal environmental impact.

\section{State of the art}

The need to produce construction materials with favourable sustainability characteristics and the necessity to protect and improve existing earthen structures, as well as to preserve local building cultures, have led scientists across the world to turn their attention towards earth-based materials and especially adobe. Since most of the building techniques related to earth-based materials have been systematically neglected during the past decades, there is an imminent need to "rediscover" adobe through academic research.

In our days there is a surprisingly great number of academic books and articles related to adobe. In various countries research regarding the mechanical properties of adobe, methods of improving its performance and techniques for the seismic stabilization of adobe structures has been undertaken or is in progress. However, the knowledge gained through research has not been used yet for the compilation of national or international building codes and regulations. The lack of building codes and regulations discourages architects and engineers from using adobe in the erection of new buildings and has created the impression that earth-based materials are inappropriate and not reliable for being applied in modern structures. In some countries, where adobe is applied for the construction of new buildings, local or national directive documents have been developed. These are usually based on local building tradition and quite often architects and engineers consider them to be inadequate for designing structures that will be able to comply with modern day standards.

In Cyprus, adobe has been rapidly displaced by industrialized materials (mainly concrete and fired bricks) over the past few decades. The construction techniques related to earthen materials have therefore been downrated. Unfortunately, local research related to earth-based materials is still at a very early stage and few data are available. Despite the fact that adobe construction is considered to be an ancestral technique, no serious attempt has been made yet to evaluate the current state of adobe structures, to assess the properties of local adobes and to evaluate future uses of the material in the building industry. 
The University of Cyprus has recently put forward a research program, which aims to examine the island's adobe structures. The main targets of this program are to study the mechanical properties of adobe, to develop alternative ways for improving the performance of the material and to analyse the structural behaviour of adobe structures, in order to determine how existing adobe buildings can be upgraded and how the material can be applied to modern construction. This paper reports the first findings of the research, which include a review of the use of adobe in Cyprus and of the main factors of deterioration of adobe structures on the island. It also presents methods of restoring adobe buildings and the results of a series of laboratory tests aiming to measure the compressive strength of adobes from two local manufacturers.

\section{Use of adobe in Cyprus}

In Cyprus, adobe was continuously used for construction from the prehistoric times until the mid $20^{\text {th }}$ century. In urban areas the application of the material ceased in the 1950s, whereas in rural areas people continued using adobe until the 1960s [5]. Adobe was used extensively on the island mainly because it was a low-cost and easy to manufacture and apply material. Furthermore, adobe had high thermal capacity, thus contributing to greater thermal comfort. The good thermal and insulation properties of the material were considered to be essential, in order to cope with the arid climate of Cyprus. The main reasons why the technique disappeared during the second half of the $20^{\text {th }}$ century are the social and economic changes that occurred in the Cypriot society. An extensive heritage of earth buildings was largely lost as a result of agricultural improvements and rural depopulation, while traditional skills were made obsolete by the industrialization of the construction industry. People did not aspire to earth buildings and adobe became denigrated as a product of the past. Nowadays, adobe is only used for the conservation and restoration of historic and traditional earthen buildings. It is worth mentioning that a rare exception, where adobe has been used for the erection of a contemporary building, was noted in the village of Athienou at the Larnaca district.

Adobe is encountered as the basic construction material mainly in the lowland regions of Cyprus, which are rich in soil. It was also extensively used in seaside areas, such as Limassol and Larnaca. In the semi-mountainous and mountainous regions of the island, where arable soil is scarce, the people preferred to use stone for the construction of buildings and therefore adobe structures are not that common. However, in mountainous areas where local stone is extremely difficult to work (e.g. the Ophiolite Zone in the Troodos range), adobe is encountered in many structures, coexisting with stone.

The material was used, almost exclusively, for the construction of load bearing walls (fig. 1). In some mountainous regions it was used to form the upper part of load bearing masonry walls. Occasionally it was employed for the construction of partition walls. Before the erection of the walls started, continuous foundations were first laid. In order to form the foundations and the base of the walls, a trench was dug and was filled with a mixture of lime, 
riversand and gravel $[6,7]$. Gravel from the river and limestone were also thrown into the ditch, forming a stone base that projected from the ground. The stone base of adobe walls was $100-150 \mathrm{~cm}$ high and rose $10-100 \mathrm{~cm}$ above the ground level. It was usually about $40 \mathrm{~cm}$ thick, but there are cases where it could be 80 $100 \mathrm{~cm}$ thick [6,7]. The thickness of mud brick walls ranged from $30 \mathrm{~cm}$ (for partition walls in the interior of structures) to $50 \mathrm{~cm}$ (for load bearing walls) [7]. Adobe bricks were laid with the application of a straw-based earth mortar, which was made in the same way as the mixture used for preparing the bricks, the only difference being that the earth was free of any stones and finer straw was usually used. It has been observed that the builders of the past used a very thin layer of mortar in the construction of the walls. In order to improve the structural behaviour of adobe buildings, wooden binding beams (mantosia) were installed on the outer side of the wall and at the height of the lintels of the openings on the upper storeys. In some cases, relieving arches were constructed using adobe bricks over the openings and above the wooden lintels. After the walls were built, they usually remained without plaster for about a year to "settle" [5,7]. Adobe masonry was coated on the interior with gypsum plaster and on the exterior with lime-based plaster or mortar mixed with straw. When plaster coatings were applied on the masonry, wooden wedges were placed at dense intervals all over the surface of the wall, in the joints between the adobe bricks.
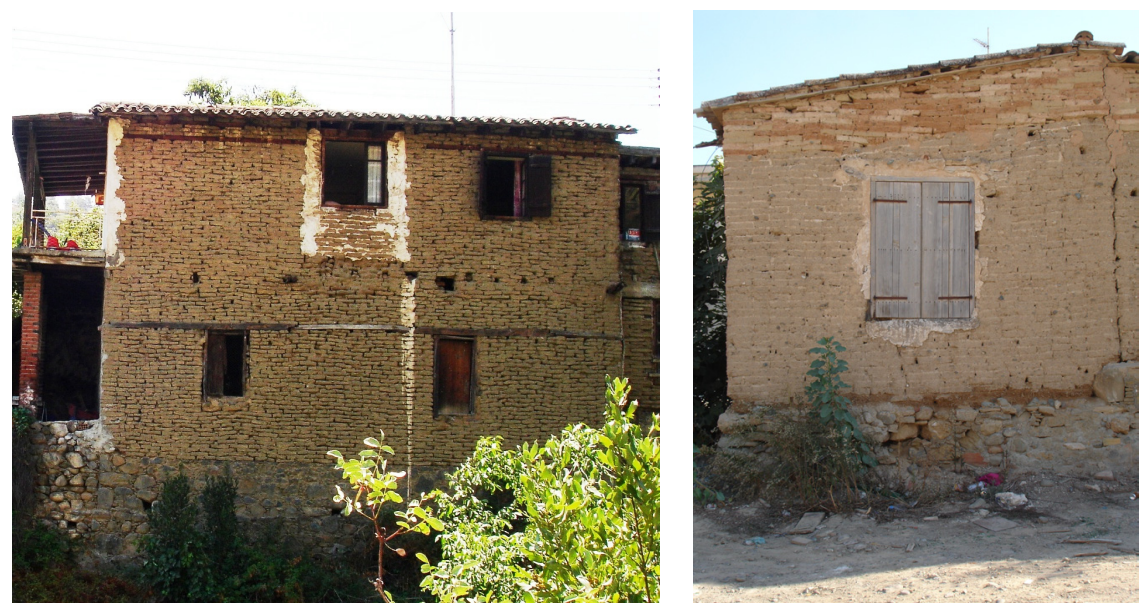

Figure 1: Local traditional buildings with load bearing walls composed of adobe masonry.

\section{Factors of deterioration of adobe structures}

The durability of adobe structures is largely dependent on factors such as construction practices, soil selection and local climatic conditions. In Cyprus, the deterioration of mud brick structures has been largely attributed to cracking, erosion, spalling at the base and loss of mechanical properties. In most cases, 
these deterioration processes are directly or indirectly related to the presence of excess moisture. The following types of structural damage have been recorded.

\subsection{Deterioration of the base of the wall}

This type of damage (fig. 2) is caused by the penetration of ground water into the wall due to the fact that most traditional adobe structures do not have waterproof foundations. The result is the formation of continuous deep horizontal fissures on the boundary between the stone base and the adobe wall. The loss of supporting area on the base of the wall introduces load-bearing eccentricities into the structure, which may lead to the failure of the structural element. It also causes the loss of connection between the wall and it's coating, thus resulting to the bulging, cracking and detachment of plaster.

\subsection{Deterioration at the top of the wall}

When the upper part of adobe structures is not adequately protected or the protection mechanism fails, water coming from the overflow of gutters, or through the roof due to the lack of maintenance, penetrates into pre-existing micro cracks causing the disintegration of the material. The action of rainwater on the upper part of walls leads to the formation of fissures and cracks (fig. 2). It also causes deterioration of surface coatings and deformation of roof beams.
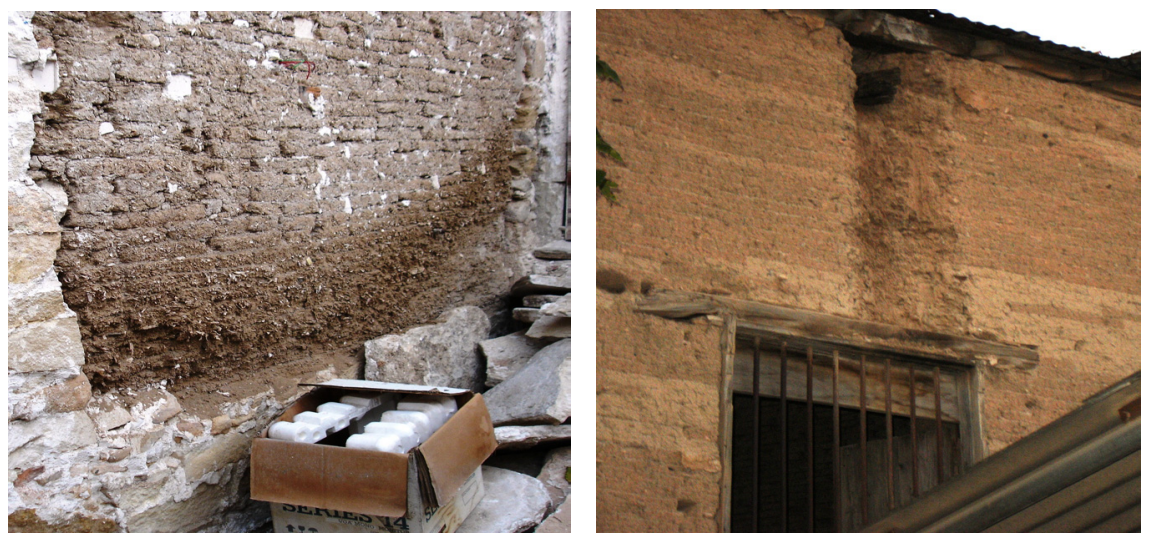

Figure 2: Deterioration at the base of an adobe wall (left) and characteristic fissure on the upper part of an adobe wall caused by the action of rainwater (right).

\subsection{Disintegration of adobe}

Disintegration (fig. 3) occurs when the soil forming the adobe loses cohesion and the binding material (straw or seaweed) rots. The process starts when water penetrates the body of the wall or when it runs directly on the surface of adobe masonry that is not protected by any kind of coating. Depending on the 
temperature and humidity conditions of the atmosphere, trapped moisture can evaporate, suffer freeze-thaw cycles, condensate or deposit soluble salts within the masonry. These mechanisms result in the formation of internal cracking and cause the particles of the material to lose their cohesion and detach from the rest of the body [5]. Quite often, dampness causes the timber wedges, which provide cohesion between the surface of the wall and the coatings, to swell. Consequently, large parts of plaster are detached from the wall leaving the surface of adobe exposed to weather conditions. When water washes down the surface of uncoated adobe masonry, further erosion occurs.
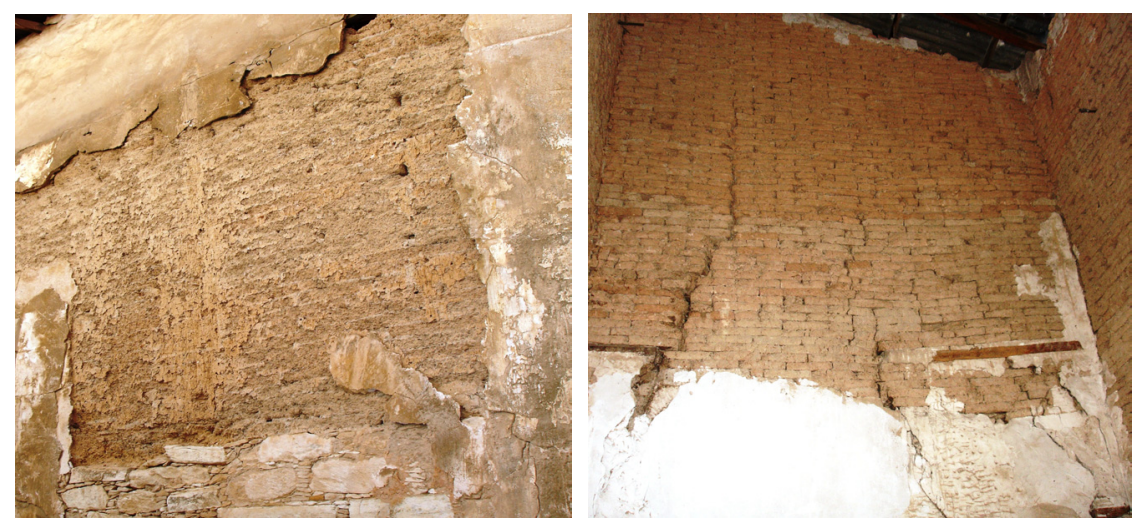

Figure 3: Disintegration of adobe and loss of the protective coating as a result of trapped moisture and water washing down the surface of the wall (left). Various vertical and diagonal cracks in the body of an adobe wall (right).

\subsection{Cracking}

Cracking in adobe structures is caused by horizontal movements in plane or out of the plane of the walls, bending of the walls and support displacement. These conditions are generated by various reasons such as earthquakes, ground vibrations, excessive deformations of the floor or roof structure, erosion of the wall's base, undermining of the foundations due to poor drainage, ground settlement, vegetation growth etc. The aforementioned processes can cause the formation of diagonal or vertical cracks in the body of the wall (fig. 3), the creation of diagonal cracks above lintels and the development of detachment cracks (fig. 4) at the wall corners [8]. In extreme cases they may cause the outof-plane collapse of a wall, the failure of wall corners, the collapse of parapets or even the collapse of the roof due to the loss of support [8].

\subsection{Bulging or slumping of walls}

This type of structural damage can be caused by poor binding between adjacent walls or the introduction of eccentricities in the structure during its erection. The 
application of materials with different mechanical properties within the body of adobe walls can also result in bulging or slumping. Additionally, slumps and bulges may occur as a result of the deterioration of the base of the wall (fig. 4). Moreover, settlement can lead to local buckling or the development of bulges. Occasionally, bulging is caused by the growing roots of vegetation and trees that penetrate within the main body of adobe walls.

\section{Techniques used for the restoration of adobe structures}

In Cyprus there are currently no building codes or regulations to guide architects and engineers in the restoration of traditional adobe buildings. Most of the techniques that are being applied derive from local building tradition and are slightly modified to accommodate the use of modern materials. In some cases they come from techniques suggested by scientific work published in other countries. Quite often, local engineers prefer to apply techniques that aim to produce an instant effect. However, this effect is usually temporary and does not result in the efficient restoration of an adobe structure.
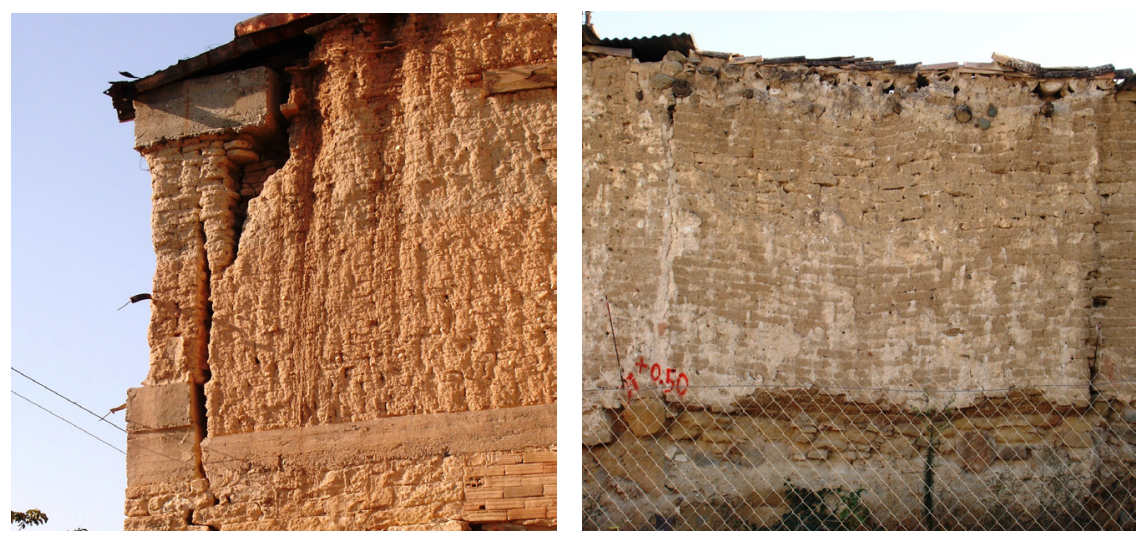

Figure 4: Building exhibiting various forms of structural damage such as the deterioration of its upper part, the disintegration of adobe and the formation of detachment cracks (left). Slumping of adobe wall that has been caused by the deterioration of its base (right).

The damaged base of adobe walls is usually repaired by replacing the disintegrated material with new adobe. Replacement is executed in steps while temporary supports assure the stability of the wall. When the adobe has been superficially disintegrated it is often scratched to the hard surface and a new coat of plaster is applied. In order to prevent rising dampness, mainly two techniques are currently employed. The first is to install a waterproof membrane between the stone base of the wall and the adobe bricks. In this case, damp can bypass the sealed area of the wall through the mass of the wall or the internal filling of the floors. In addition, the base of the wall below the membrane still remains 
exposed to moisture. The second technique aims to create an impermeable barrier in the stone base of the wall by injecting water-repellent compounds into a series of pre-drilled holes. In practice, the creation of an impermeable barrier is hardly ever achieved due to the fact that the base is constructed of rubble masonry and the water-repellent compounds cannot penetrate into all parts of the rubble core.

When deteriorated or damaged material is located in a part of a structure, the area is locally demolished and reconstructed. Quite often, readily available fired bricks are used instead of new adobe bricks because they are considered to be more durable. A similar technique is often used for repairing cracks. A small part of the wall, on both sides of the crack, is demolished and rebuilt using masonry units. In some cases, the cracks are treated using grouting injections. This technique can only achieve the transfer of compressive stresses if the crack is fully sealed. In addition to filling the crack, stitching may also be used to transfer stresses from one part to the other. Wooden beams and steel straps are the most common materials used in this case (fig. 5).
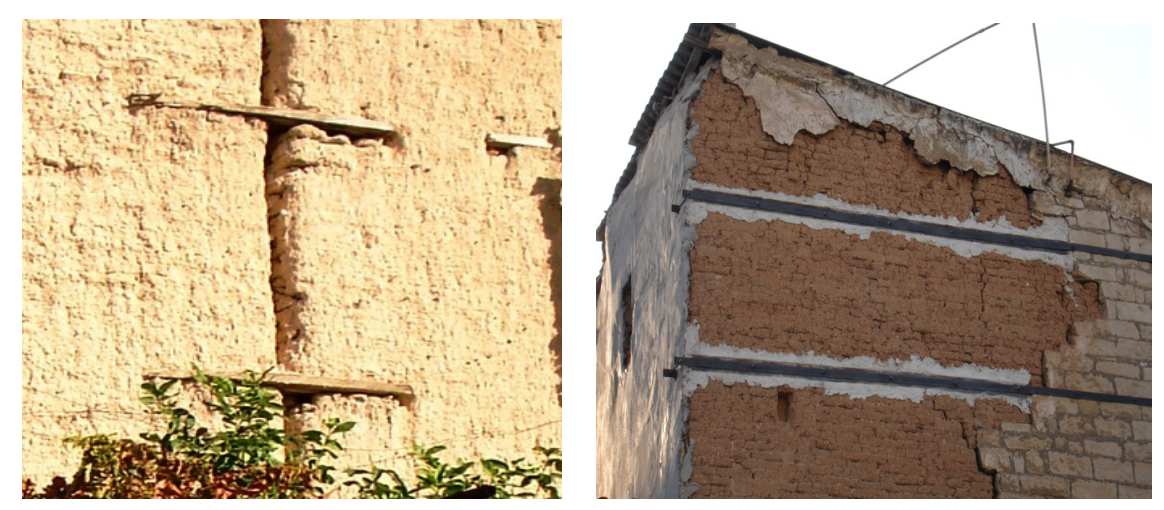

Figure 5: Installation of timber beams for the treatment of a vertical discontinuity (left). Steel straps that have been installed in an adobe structure to repair cracking (right).

Nowadays, the coatings of adobe structures are usually restored by using more or less the traditional technique. This involves the installation of wooden wedges or nails on the surface of the walls and the application of gypsum plaster in the interior of the building and lime-based plaster on the exterior. The earth rendering that was commonly applied in the past is nowadays rarely used. In some cases, in order to achieve better cohesion between the adobe masonry and the coating, fencing wire is attached on the surface of walls using nails. This technique has proven to be inefficient, because very often moisture affects the nails retaining the fencing wire and as a result the whole surface of the coating collapses. The application of cement-based coatings is occasionally encountered in adobe structures. Apart from the aesthetically displeasing effect, this technique has catastrophic results on the long term. Impermeable cement-based coatings trap moisture within the masonry causing the disintegration of the 
material and accelerating the negative effects of rising damp. In addition, they produce soluble salts that severely damage adobe.

Usually, the first step for strengthening adobe structures is the restoration of the various building elements to their original size and state. A very common technique is to improve the interlocking of the walls at the corners either by installing timber beams (fig. 6) or by the local demolition and rearrangement of adobes to ensure keying. In many cases the interlocking of the structure's walls with the floor and roof is improved by installing wooden beams and poles or a combination of timber elements and steel straps. This enables the floors and the roof to act as a diaphragm that provides lateral support and resists out-of-plane movements. Strengthening is also achieved by the installation of additional resisting elements. These are usually wooden ring beams that are placed on the upper part of the wall. It must be noted that apart from the techniques mentioned above, the construction of reinforced concrete frames has been encountered in some buildings. This is a non-reversible, intrusive type of intervention that changes the structural system of the building and alters the traditional character of adobe structures.
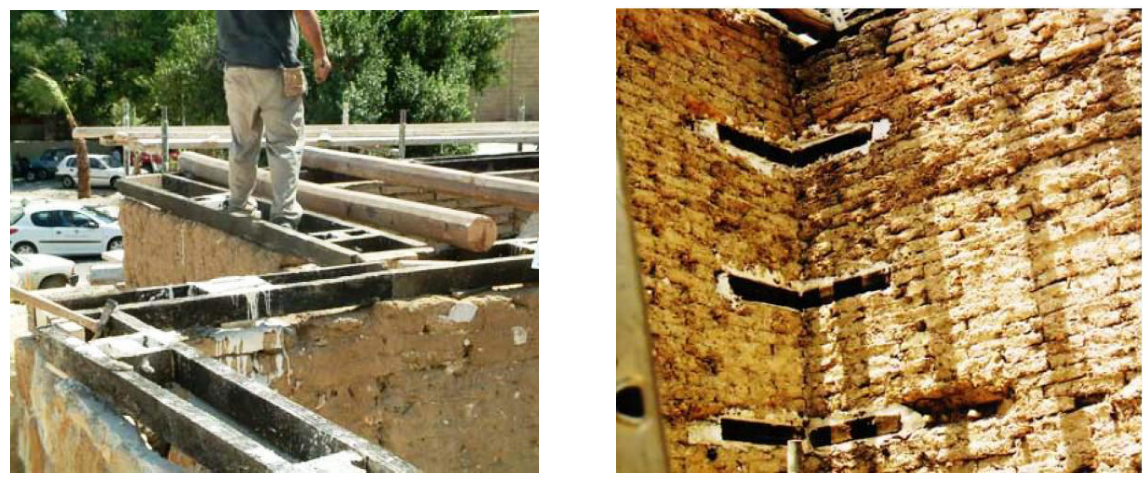

Figure 6: Installation of a wooden ring beam on the upper part of an adobe structure (left) and of timber beams at the corner of adobe walls (right).

\section{Laboratory tests}

Following the main objectives of the research program that has been established by the University of Cyprus, a series of compression tests has been performed on adobe bricks coming from different local manufacturers. Unfortunately, no standard testing procedure exists for assessing the compressive strength of adobe bricks. Various sizes of test specimens are recorded in international bibliography, depending on local manufacturing techniques and the dimensions of adobes. The testing procedure followed and the dimensions of the specimens used derive from the scientific work published in other countries.

The bricks that have been tested in the laboratories of the University of Cyprus have been made in the areas of Athienou and Lympia by two adobe 
makers ( $\mathrm{A}$ and $\mathrm{B}$ ) who use different manufacturing techniques. The compression tests were performed using two different machines. In order to have comparable results, tests were carried out on various sizes of specimens. These included $4 \times 4$, $5 \times 5,10 \times 10$ and $20 \times 20 \mathrm{~cm}^{2}$ specimens. Each test sample (adobe brick) was cut into specimens in dry conditions using a masonry saw. The surfaces of the specimens were smoothened to achieve a uniform distribution of the compressive stresses during the tests. A total of 99 specimens were tested, which were cut from 11 brick samples (4 samples from batch 1 of manufacturer A, 2 samples from batch 2 of manufacturer A and 5 samples from batch 1 of manufacturer B). Table 1 summarizes the results obtained. The table reports the mean value and the coefficient of variation (=standard deviation/mean value) of the compressive strength for the specimens cut from each sample.

Table 1: $\quad$ Mean values (MPa) and coefficients of variation of compressive strength obtained for the tested samples. Samples are referenced as "Xa.b", where " $X$ " refers to the manufacturer (A or B), " $a$ " denotes the batch number and " $b$ " indicates the sample (adobe brick) number.

\begin{tabular}{|c|c|c|c|c|c|}
\hline \multirow{2}{*}{$\begin{array}{c}\text { Sample } \\
\text { (number of } \\
\text { specimens) }\end{array}$} & \multicolumn{4}{|c|}{ Compressive strength mean value (coefficient of variation) } \\
\cline { 2 - 6 } & $\begin{array}{c}4 \times 4 \mathrm{~cm}^{2} \\
\text { specimens }\end{array}$ & $\begin{array}{c}5 \times 5 \mathrm{~cm}^{2} \\
\text { specimens }\end{array}$ & $\begin{array}{c}10 \times 10 \mathrm{~cm}^{2} \\
\text { specimens }\end{array}$ & $\begin{array}{c}20 \times 20 \mathrm{~cm}^{2} \\
\text { specimens }\end{array}$ & $\begin{array}{c}\text { Overall } \\
\text { (weighted) }\end{array}$ \\
\hline A1.1 (9) & - & $1.0(32 \%)$ & $1.7(4 \%)$ & - & $1.4(29 \%)$ \\
A1.2(12) & - & $1.4(16 \%)$ & $3.6(15 \%)$ & - & $2.5(49 \%)$ \\
A1.3(8) & - & $1.5(12 \%)$ & - & - & $1.5(12 \%)$ \\
A1.4 (4) & - & - & $2.3(53 \%)$ & - & $2.3(33 \%)$ \\
A2.1 (6) & - & - & $1.8(16 \%)$ & - & $1.8(16 \%)$ \\
A2.2(5) & - & - & $1.7(7 \%)$ & - & $1.7(7 \%)$ \\
\hline B1.1 (14) & - & $2.8(13 \%)$ & $3.0(21 \%)$ & - & $2.7(18 \%)$ \\
B1.2(12) & - & $2.4(12 \%)$ & $2.7(27 \%)$ & - & $2.6(22 \%)$ \\
B1.3(11) & $1.9(13 \%)$ & - & $3.5(33 \%)$ & $1.02(0 \%)$ & $2.4(46 \%)$ \\
B1.4 (7) & $2.4(72 \%)$ & - & $5.1(9 \%)$ & $1.00(0 \%)$ & $3.4(51 \%)$ \\
B1.5(10) & $2.4(16 \%)$ & - & $3.8(4 \%)$ & $1.04(0 \%)$ & $2.9(35 \%)$ \\
\hline
\end{tabular}

From these results it is evident that there is a great variability in the compressive strength of adobe bricks. Samples from the two different manufacturers exhibit very different mechanical behaviour. This is probably due to differences in the quality of soil used, the mix design and the manufacturing technique. Even samples within the same batch show different results (e.g. see the results of Table 1 for samples A1.1 and A1.2). This is characteristic of the inherent inhomogeneity and randomness of the material. In order to draw more valid conclusions on the mechanical behaviour of adobe, additional tests are needed, as well as an extensive physicochemical study of the material itself. 


\section{Conclusions}

Adobe is one of the oldest building materials. Although technologically simple, it has the potential to produce durable structures of a sustainable nature, provided that it is protected from the factors causing its deterioration. However, the absence of building codes and regulations for adobe structures makes it difficult for architects and engineers to adapt the material in modern construction. Furthermore, the inhomogeneity and lack of extensive information on adobe bricks affects their reliability in use and implies that research, on local level, is needed. Future work should focus on the characteristics of adobe materials and on the strengthening of adobe structures. Through such research adobe may be established as an environmentally friendly, high quality material with many benefits and extensive applications in the construction industry.

\section{References}

[1] Keefe, L., Earth Building - Methods and Materials, Repair and Conservation, Taylor \& Francis: London and New York, 2005.

[2] Morton, T., Earth Masonry - Design and Construction Guidelines, IHS BRE Press: Watford, 2008.

[3] Houben, H. \& Guillard, H., Earth Construction - A Comprehensive Guide, ITDG Publishing: London, 1994.

[4] Brown, P.W. \& Clifton, J.R., Adobe I: The Properties of Adobe. Studies in Conservation, 23(4), pp. 139-146, 1978.

[5] Sinos, S., A Review of Cyprus' Vernacular Architecture, Athens Press: Nicosia, 1976.

[6] Demetriou, T., Pattichis, A., Constantinides, A. \& Papadouris G., Restoration and Maintenance of Traditional Settlements, Cyprus Civil Engineers and Architects Association: Nicosia, 2006.

[7] Mud Brick Walls, Traditional Mediterranean Architecture, CORPUS, Euromed Heritage, http://www.meda-corpus.net/eng/gates/PDF/ F2/A07_CHY.PDF

[8] Adobe Construction, Catholic University of Peru, http://www.worldhousing.net/uploads/adobe.pdf?pr=Array 